\title{
Non-Surgical Interventional Treatment of Cervical and THORACIC RADICULOPATHIES
}

\author{
Richard Derby, MD, Yung Chen, MD, Sang-Heon Lee, MD, PhD, Kwan Sik Seo, MD, and Byung-Jo Kim, MD, PhD \\ Cervical and thoracic radiculopathies \\ are among the most common causes of \\ neck pain. Outcome studies of conservative \\ treatments have shown varying results and \\ have not been well controlled or systematic. \\ Although there has not yet been a non- \\ surgical interventional procedure developed \\ with the therapeutic efficacy of open surgery, \\ conservative procedures can offer substantial \\ benefits, are less invasive, and avoid \\ surgical complications. While more invasive \\ procedures may be appropriate when \\ conservative treatment fails, prospective \\ studies evaluating cervical and thoracic \\ radiculopathy treatment options would help \\ guide practitioners toward optimally cost- \\ effective patient evaluation and care. \\ Keywords: Cervical radiculopathy, tho- \\ racic radiculopathy, non-surgical intervention- \\ al treatment, disc herniation, percutaneous \\ decompression, epidural steroid injection
}

Spinal neck and low back pain have a lifetime prevalence of $65 \%$ to $80 \%$ (13). Linton et al (3) have shown a $44 \%$ prevalence of neck pain in the general population. The prevalence of neck pain is the same, or higher, than low back pain $(4,5)$. One of the common causes of neck pain is cervical and thoracic radiculopathy, a pathologic process involving the nerve root. Radiculopathy typically originates from mechanical root compression due to degenerative spine changes such as disc herniation and spondylosis (6). Less common causes include tumor, trauma-induced root avulsion, viral inflammation or connective tissue disease (7). A thorough history, physical examination, and testing, which includes electrodiagnostic and imaging studies may distinguish radiculopathy from other pain sources, such as soft tissue pathology.

Thoracic radiculopathies may be confused clinically with intra-abdominal disorders. Symptomatic thoracic disc herniations account for $<1 \%$ of all symptomatic disc herniations. As a result, tho-

From Spinal Diagnostics and Treatment Center, Daly City, California. Address Correspondence: Byung-Jo Kim, MD, PhD, Spinal Diagnostics and Treatment Center, 901 Campus Drive, Suite 310, Daly City, CA 94015

E-mail:kim@spinaldiagnostics.com

Disclaimer: No outside funding was provided in preparation of this manuscript.

Conflict of Interest: None

Acknowledgement: Manuscript received on 3/5/04. Revision submitted on 6/14/04. Accepted for publication on $6 / 14 / 04$. racic radiculopathy has been infrequently reported and described as uncommon $(8$, 9). In contrast with lumbar radiculopathy, for which natural history and outcome are well-understood (10), the outcome of patients with cervical or thoracic radiculopathy is unknown. Study results vary substantially. While some studies demonstrate that two-thirds of patients undergoing conservative treatment experience persistent pain $(11,12)$, a multicenter physiotherapy trial showed that $92 \%$ of 493 patients undergoing cervical traction received pain relief (13).

Surgery, typically involving laminectomy and microdiscectomy, has been shown to have excellent clinical outcomes in patients with disc extrusion and neurological deficits. However, patients with disc herniation $<6 \mathrm{~mm}$ have fair or poor surgical outcomes (14). In addition, conventional open disc surgery entails risks of general anesthesia, nerve damage, epidural fibrosis, chronic postoperative pain syndrome and adjacent spinal instability $(15,16)$.

The historical background and reliability of non-surgical interventional therapeutic methods for cervical and thoracic radiculopathy are discussed in the following sections.

\section{Clinical Symptoms and Signs}

\section{Cervical Radiculopathy}

Classic symptoms of cervical radiculopathy include pain and tingling in the neck and/or upper extrem- ity, numbness, and eventually weakness. The most common cause is degenerative spine disease (e.g., disc herniation and spondylosis) affording neuroforamen narrowing and radicular compression. In an epidemiological survey of cervical radiculopathy, (17) $68.4 \%$ of cases involved spondylosis, disc protrusion or both. Disc protrusion was confirmed in $21.9 \%$ of patients. Monoradiculopathy involving the $\mathrm{C} 7$ nerve root is most frequent, followed by $\mathrm{C} 6, \mathrm{C} 8$, and $\mathrm{C} 5$, in descending order. Neurological findings can include weakness on manual muscle testing, decreased sensation in dermatomal distributions, and diminished or absent muscle stretch. Spurling's test(18), involving lateral neck bending and extension while applying pressure to the spine, may be utilized. While Spurling's and similar tests are not particularly sensitive, they are specific for cervical radiculopathy diagnosed by electromyography (EMG) (19). Wainner et al (20) found that upper limb tension testing was useful for ruling out cervical radiculopathy.

\section{Thoracic Radiculopathy}

Thoracic radiculopathy patients commonly present with "band-like" chest pain (21). Lower limb pain may also be presented. Weakness is relatively uncommon. Findings of abdominal wall bulging, simulating hernia due to weakness of the abdominal wall muscle, may suggest thoracic radiculopathy (22). Vague and poorly localized abdominal "visceral" pain is a common 
presenting symptom in mid and low thoracic radiculopathy. Pain is frequently associated with marked weight loss, but carries a good prognosis for recovery (23). The most common cause of thoracic radiculopathy is diabetes mellitus. Less common causes of thoracic radiculopathy include scoliosis, metastatic tumor, inflammation induced by herpes zoster, disc herniation and tuberculosis (24-26).

A $\mathrm{T} 1$ radiculopathy requires greater attention due to the similarity of clinical findings to C8 radiculopathy (27). Several characteristics such as diminished sensation in the axilla, motor deficit involving only the intrinsic muscles of the hand, and Horner's syndrome may distinguish T1 radiculopathy (28).

\section{DIAGNOSIS}

\section{Electrodiagnosis}

Cervical Radiculopathy. Electrodiagnosis may distinguish cervical radiculopathy from other etiologies of neck and shoulder pain $(29,30)$. Needle EMG is putatively the most sensitive and specific component of the electrodiagnostic examination for axonal loss radiculopathy (31). Axonal loss also can be detected as abnormal spontaneous activity in the involved musculature, when the nerve lesion is severe enough (32).

There are limitations to the needle study. Abnormalities occur when injury produces motor axon loss and/or conduction block. Lesion level is determined by abnormal findings in a specific myotomal pattern. It is important to examine different peripheral nerve innervated muscles within the same myotome. Involvement of both proximal and distal muscles may differentiate radiculopathy and peripheral polyneuropathy.

Paraspinal EMG may differentiate radiculopathy and plexopathy (33) since the paraspinals are supplied by the dorsal primary rami proximal to the dorsal root ganglion. Care should be taken to study the highly specific deep paraspinal layers (34). Dillingham et al (35) recommended including paraspinals in cervical screening. Abnormal findings may facilitate radiculopathy detection. Nerve conduction studies, $\mathrm{H}$ - and F-responses, and evoked potential studies may help differentiate radiculopathy from other neuromuscular problems.

Thoracic Radiculopathy. Intercostal nerve conduction study can be used for evaluating thoracic nerves, but the risk of pneumothorax $(8.8 \%)$ has limited popular use of the technique (36). The muscles for evaluating thoracic nerve root involvement are paraspinal, intercostal, and abdominal muscles. Electrophysiologic examination in patients with putative thoracic radiculopathy is difficult and problematic. Wide exploration of several levels above and below the suspected level should be performed bilaterally.

Electrophysiologic and clinical findings should be carefully assessed in patients with diabetes mellitus due to frequent non-symptomatic spontaneous activity in multilevel paraspinals. Care should be taken to optimize muscle relaxation. Vague findings obtained without relaxation should be excluded from the final diagnosis. Attention to active muscle insertional activity during needle examination at intercostal or abdominal muscles is required to avoid inadvertent pleural or peritoneal puncture.

\section{Imaging Studies}

Myelography. Although myelography was considered the gold standard for evaluating neural axis compression, computed tomography (CT) and magnetic resonance image (MRI) have superseded this technique. Myelography is indicated when MRI is not possible, e.g., in patients with certain ferromagnetic implants.

Magnetic Resonance Image and Computed Tomography. Studies using MRI and CT scanning can be considered precise when signs and symptoms are radicular and pain originates from a compressed nerve root. In the absence of objective neurological deficits or electrodiagnostic findings, the correlation of MRI findings and symptoms is imprecise.

\section{TREATMENT}

Outcome studies of conservative treatment for cervical and thoracic radiculopathies have shown various results (11-13). Referral center-based studies have shown persistent pain and incapacity in two-thirds of patients treated conservatively $(11,12)$. When legitimate incapacitating symptoms continue despite conservative treatment attempts, more invasive spinal procedures and intradiscal treatment may be appropriate.

\section{Epidural Steroid Injection}

Radicular pain results from me- chanical compression and/or chemical irritation of a nerve root. Inflammation may be a key factor, even in the presence of mechanical compression. To reduce inflammation, therapeutic epidural steroid injections (ESIs) may be utilized. Injections typically include antiinflammatory agents such as corticosteroids, which reduce the rate of prostaglandin synthesis via phospholipase A2 inhibition (38). Corticosteroids may also impair cell-mediated and immunologic responses (39, 40), block nociceptive C-fiber conduction (41), reduce ectopic discharges from pathologic nerve roots, and block the vascular response of vasonervorum to inflammatory agents (42).

Cervical Epidural Steroid Injections. Cervical ESIs have been used to treat neck, shoulder and upper limb pain resulting from radiculopathy (43). To our knowledge, no controlled, blinded cervical ESI study including a placebo group or an accounting of associated treatments or therapies has been published. Clinical trials demonstrate variable results. Rowlingson and Kirshenbaum (44) reported $64 \%$ efficacy in a retrospective analysis of 25 patients receiving cervical ESIs. Sixteen patients described $>75 \%$ improvement. Six patients (24\%) reported complete resolution of presenting symptoms. Shulman (45) reported 76\% efficacy in 96 patients when successful outcome was defined as $\geq 50 \%$ pain relief.

Ferrant et al (46) studied cervical ESI outcomes in 235 patients with neck pain. At least $50 \%$ pain relief was obtained in $40 \%$ of patients. The best outcomes occurred in patients with true radiculopathy, including appropriate symptoms, and patients with radicular symptoms associated only with a correlative structural abnormality. Approximately $62 \%$ of patients with true radiculopathy described $>50 \%$ pain relief.

Bush and Hillier (47) studied clinical outcomes in 68 patients with cervical radiculopathy managed by serial periradicular/epidural corticosteroid injection. Data were gathered via telephone interview an average of 39 months after initial presentation (range: 4-112 months). Although all 68 patients were potential surgical candidates, $100 \%$ recovered satisfactorily without requiring surgical intervention. Forty-eight patients $(76 \%)$ did not experience any arm pain following treatment.

Thoracic Epidural Steroid Injec- 
tion. Thoracic epidural block for anesthesia has been widely used for thoracotomy, cardiac surgery, management of cancer pain and spinal cord stimulation. (4850) Thoracic ESIs have been shown to provide good results for neurogenic pain caused by herpes zoster, trauma or diabetic neuropathy $(51,52)$.

Since thoracic radiculopathy has been infrequently reported and described as uncommon, there is no in-depth study reporting outcome or efficacy available in the National Library of Medicine PubMed database.

\section{Percutaneous Disc Decompression}

Minimally invasive techniques providing percutaneous access to pain-generating discs have been developed to treat radiculopathy induced by disc herniation. Chemonucleolysis, percutaneous nucleotomy, intradiscal laser discectomy, and Nucleoplasty incorporate this approach. These techniques have been utilized for treating radiculopathy via partial removal of the nucleus pulposus to reduce intradiscal pressure. Partial removal of the nucleus pulposus has been shown to decompress herniated discs, reducing pressure on nerve roots and affording relief from discogenic pain in some cases (53-55).

Chemonucleolysis. Chemonucleolysis was the first percutaneous intradiscal therapy. Injection of chymopapain affords enzymatic dissolution of the nucleus pulposus via the hydrolysis of proteoglycans (56). This procedure predominantly relieves radicular pain rather than neck or upper back pain. Proper patient selection is paramount. Classic indications are symptomatic disc displacement demonstrated by MRI, CT, and/or myelography and absence of other major causes of symptoms.

Over the 20 years following its introduction, the efficacy of chymopapain was examined in clinical trials. Hoogland and Scheckenbach (57) reported on a series of patients with cervical disc herniation and radicular pain treated by low-dose chemonucleolysis combined with automated percutaneous nucleotomy. At follow-up of at least 1 year, 19 of the first 22 patients showed good or excellent results. There were no intra- or postoperative complications in approximately 100 patients. Though rare, fatal complications such as anaphylaxis, transverse myelitis, cartilaginous endplate damage and hemorrhage were reported $(56,58,59)$. Anaphylactic immunologic reaction induced by chymopapain protein antigens and neurotoxicity were suggested as the main causes of adverse effects (60, 61).

Although less allergenic enzymes have been developed (e.g., chondroitinase $A B C$ ), these agents are restricted to animal studies $(62,63)$ or there are insufficient data to support clinical use (64). Despite unproven safety, some physicians continue to state that chemonucleolysis is effective and economical given appropriate patient selection and proper surgical technique (58).

Percutaneous Nucleotomy. Percutaneous discectomy techniques utilizing manual nucleotomy through a cannula have been in use since the 1970s $(15,53,65)$. Specialized forceps and curettes introduced by Hijikata et al (66) in 1975, permitted disc removal through a cannula placed percutaneously on the posterolateral aspect of the annulus. Some development in equipment continued, and published studies demonstrated safety and efficacy.

Bonaldi et al (67) reported successful use of nucleotome for percutaneous disc decompression in 15 patients with cervical herniated nucleus pulposus who refused or were ineligible for open surgery. A safe percutaneous approach to cervical discs useful for biopsy and treating patients at high risk for general anesthesia was suggested. Kotilainen (68) reported outcomes for three patients with cervical disc herniation treated with manual percutaneous nucleotomy. This technique has not been widely accepted due to several factors, including high complication rate, technical difficulty, and large cannula size (54).

Intradiscal Laser Discectomy. Intradiscal laser discectomy employs laser energy to vaporize part of the nucleus volume. Consequent debulking of the disc space reduces discal pressure and permits the regression of disc protrusion. Laser intradiscal procedures were introduced in the 1980s (69). Various laser types have been evaluated for effectiveness, safety and ease of use. $(55,70)$ Common lasers for disc decompression include potassium-titanyl-phosphate (KTP), neodymium:yttrium-aluminumgarnet $(\mathrm{Nd}$ : YAG), and holmium:YAG (Ho:YAG). Laser choice depends on the ability to deliv- er energy through a fiberoptic system, tissue absorption/ablation properties, and the amount of thermal generation and spread. Although various complications from thermal damage are possible, these may be avoided when the procedure is correctly performed (71).

Laser discectomy yields variable success rates (70, 72, 73). Siebert (74) reported a preliminary experience of laser discectomy in 31 patients with herniated cervical disc, and suggested that treatment of cervical discs is a viable therapy. Chiu et al (75) demonstrated that percutaneous microdecompressive endoscopic cervical discectomy with laser thermodiscoplasty is safe and effective for the treatment of cervical disc herniation. A 94.5\% success rate was obtained in 200 patients carefully selected thorough diagnostic MRI, CT, and electromyography correlated with signs and symptoms.

Disadvantages of percutaneous laser nucleolysis include the relative expense of the procedure and inadequate temperature control causing nerve root, vertebral body and endplate damage (76-78). As a result, laser discectomy currently has a limited role in the management of patients with neck pain and radiculopathy. New developments in lasers and endoscopy which improve the view field may facilitate use of this technique for percutaneous disc decompression and the treatment of more severe herniated discs.

Nucleoplasty. Nucleoplasty was approved by the Food and Drug Administration for the treatment of contained herniated discs in June 2001, and builds on the earlier percutaneous intradiscal treatment concepts of chemonucleolysis, nucleotomy and radiofrequency ablation. During conventional electrosurgery local tissue temperatures can exceed $400^{\circ} \mathrm{C}$, with rapid tissue heating, significant collateral tissue damage and deep thermal penetration. In contrast, $\mathrm{Nu}$ cleoplasty utilizes coblation technology, a non-heat-driven process. Bipolar radiofrequency energy is applied to a conductive medium (e.g., saline), permitting tissue removal with minimal collateral thermal damage.

In the lumbar spine, authors have recently found a modest temperature increase in adjacent neurovascular structures (e.g., nerve root and vasculature) at distances $>5 \mathrm{~mm}$ when coblation was performed at the disc center. Elemen- 
tary particles and low molecular weight gases are the products of the procedure, and are quickly removed from the surgical site. Thus, coblation causes a localized, low-temperature molecular disintegration. The result is volumetric nucleus tissue removal. A recent histological study demonstrated minimal collateral tissue necrosis (79).

Reductions in nuclear tissue volume on the order of $10 \%$ have been reported. Pain reduction may arise from reduced intradiscal pressure. A cadaveric study (80) by the authors demonstrated that Nucleoplasty reduced intradiscal pressure in non-degenerated contained discs with great efficiency, but had a minimal effect in severely degenerative discs where the majority of nucleus material had already desiccated. As a result, Nucleoplasty is not effective in treating severely degenerated discs.

Since Nucleoplasty is a relatively new method, few outcome studies for cervical or thoracic radiculopathy have been published. One case report described the treatment of chronic atypical cervical discogenic pain (81). Slipman et al (82) reported initial experience of Nucleoplasty in 5 patients with cervical radiculopathy. All subjects showed $75 \%$ reduction in the VAS score at all follow-up intervals. Of 5 patients, four patients returned to full time work within 2 weeks post procedure. They suggested that this intervention may result in rapid and prolonged pain relief for patients with cervical radicular pain due to an acute focal protrusion.

In the authors' experience with 9 patients with neck or upper axial back pain, with or without arm pain, results with Nucleoplasty were promising, with greater than 50\% VAS improvement at 3 months' follow up. Like other decompressive techniques, Nucleoplasty is designed to treat patients with extremity pain due to smaller disc protrusions. There is a growing trend to perform both nuclear decompression and heating treatments in the same session (84).

Despite evidence of safety (79), the authors find it imperative to carefully monitor pain or neurological symptoms in the neck and/or arm that may indicate damage to vital neural elements. If required, the physician can rapidly reposition the instrument or abort the procedure to avoid potential neurovascular damage. Excessively large volume removal may cause rapid contraction of intervertebral disc volume. As in nucleotomy, poor results may be obtained when a large nucleus volume is removed (85). In addition to mechanical factors, intradiscal thermal effects may a play a role in Nucleoplasty. Collagen remodeling and thickening, thermocoagulation of abundant nociceptors (e.g., small, unmyelinated fibers) and sensitized mechanoreceptors within symptomatic discs may be involved $(86,87)$.

Despite insufficient clinical safety data, strict patient selection seems likely to increase success rates. Selection criteria may include: normal psychometric testing, adequate disc height ( $>50 \%$ of normal), contained disc herniation $<6 \mathrm{~mm}$, and radicular symptoms.

Clinical experience with this new technology in a larger patient population and over longer follow-up periods is needed. Based upon initial data, Nucleoplasty appears to be a promising treatment for contained disc herniations $<6 \mathrm{~mm}$ with and without radiculopathy. Nucleoplasty may be a potential alternative to other minimally invasive percutaneous disc decompression procedures.

\section{CONCLUSION}

Although there has not yet been a non-surgical interventional procedure developed with the superior therapeutic efficacy of open surgery for incapacitating neck or upper back pain, these procedures are less invasive and avoid the complications of open surgery. While more invasive procedures may be appropriate when conservative treatment fails, prospective studies evaluating cervical \& thoracic radiculopathy treatment options would help guide practitioners toward optimally costeffective patient evaluation and care. New appliances and techniques to treat radiculopathic pain continue to evolve and numerous controlled studies are under way. Although these procedures have limitations, careful patient selection and proper technique may substantially increase therapeutic effect.

\section{ACKNOWLEDGEMENTS}

The authors wish to thank Todd M. Billeci at the University of California, San Francisco for editing the manuscript.

\section{Author Affiliation:}

Richard Derby, MD

Medical Director, Spinal Diagnostics and Treatment Center

Associate Clinical Professor, Divi-

sion of Physical Medicine and Reha-

bilitation

School of Medicine, Stanford University, Stanford, CA

901 Campus Drive, Suite 310

Daly City, CA 94015

E-mail: rderby@spinaldiagnostics.com

\section{Yung Chen, MD}

Physiatrist

Spinal Diagnostics and Treatment

Center

901 Campus Drive, Suite 310

Daly City, CA 94015

E-mail: ychen@spinaldiagnostics.com

\section{Sang-Heon Lee, MD, PhD}

Physiatrist \& Research Physician

Spinal Diagnostics and Treatment

Center

901 Campus Drive, Suite 310

Daly City, CA 94015

\section{Kwan Sik Seo, MD}

Physiatrist \& Research Physician Spinal Diagnostics and Treatment Center

901 Campus Drive, Suite 310

Daly City, CA 94015

\section{Byung-Jo Kim, MD, PhD}

Neurologist \& Research Physician Spinal Diagnostics and Treatment Center

901 Campus Drive, Suite 310

Daly City, CA 94015

\section{REFERENCES}

1. Cote P, Cassidy J, Carroll L. The Saskatchewan health and back pain survey: The prevalence of neck pain and related disability in adults. Spine 1998; 21:16891698.

2. Bovim G, Schrader H, Sand T. Neck pain in the general population. Spine 1994; 19: 1307-1309.

3. Linton SJ, Hallden K. Can we screen for problematic back pain? A screening questionnaire for predicting outcome in acute and subacute back pain. Clin J Pain 1998; 14:209-215.

4. Ylinen J, Ruuska J. Clinical use of neck isometric strength measurement in rehabilitation. Arch Phys Med Rehabil 1994; 75: 465-469.

5. Hellsing AL, Bryngelsson IL. Predictors of 
musculoskeletal pain in men: A twentyyear follow-up from examination at enlistment. Spine 2000; 25:3080-3086.

6. Radhakrishnan K, Litchy WJ, O'Fallon WM et al. Epidemiology of cervical radiculopathy. A population-based study from Rochester, Minnesota, 1976 through 1990. Brain 1994; 117:325-335.

7. Kelsey JL. Epidemiology of radiculopathies. Adv Neurol 1978; 19:385-398.

8. Dietze DD, Jr., Fessler RG. Thoracic disc herniations. Neurosurg Clin N Am 1993; 4: 75-90.

9. Williams MP, Cherryman GR, Husband JE. Significance of thoracic disc herniation demonstrated by MR imaging. J Comput Assist Tomogr 1989; 13:211-214.

10. Weber H. Lumbar disc herniation. A controlled, prospective study with ten years of observation. Spine 1983; 8:131-140.

11. Lees F, Turner JW. Natural history and prognosis of cervical spondylosis. $\mathrm{Br}$ Med J 1963; 5373:1607-1610.

12. Dillin W, Booth R, Cuckler J et al. Cervical radiculopathy. A review. Spine 1986; 11: 988-991.

13. Medicine BA. Pain in the neck and arm: A multicenter trial of the effects of physiotherapy, arranged by the British Association of Physical Medicine. Br Med J 1966; 5482:253-258.

14. Carragee EJ, Kim DH. A prospective analysis of magnetic resonance imaging findings in patients with sciatica and lumbar disc herniation. Correlation of outcomes with disc fragment and canal morphology. Spine 1997; 22:1650-1660.

15. Maroon JC, Quigley MR, Gleason PL. Is there a future for percutaneous intradiscal therapy? Clin Neurosurg 1996; 43:239251.

16. Onik G, Mooney V, Maroon JC et al. Automated percutaneous discectomy: A prospective multi-institutional study. Neurosurgery 1990; 26:228-232.

17. Radhakrishnan K, Litchy WJ, O'Fallon WM et al. Epidemiology of cervical radiculopathy. A population-based study from Rochester, Minnesota, 1976 through 1990. Brain 1994; 117:325-335.

18. Spurling RG, Scoville WB. Lateral rupture of the cervical intervertebral discs: A common cause of shoulder and arm pain. Surg Gynecol Obstet 1944; 78:350-358.

19. Tong HC, Haig AJ, Yamakawa K. The Spurling test and cervical radiculopathy. Spine 2002; 27:156-159.

20. Wainner RS, Fritz JM, Irrgang JJ et al. Reliability and diagnostic accuracy of the clinical examination and patient self-report measures for cervical radiculopathy. Spine 2003; 28:52-62.

21. Dumitru D, Zwarts MJ. Radiculopathies. In Dumitru D, Amato AA, Zwarts MJ (eds). Electrodiagnostic Medicine. 2nd ed. Philadelphia, Hanley \& Belfus, 2002, pp 713776.

22. Streib EW, Sun SF, Paustian FF et al. Dia- betic thoracic radiculopathy: Electrodiagnostic study. Muscle Nerve 1986; 9:548553.

23. Kikta DG, Breuer AC, Wilbourn AJ. Thorac ic root pain in diabetes: The spectrum of clinical and electromyographic findings. Ann Neurol 1982; 11:80-85.

24. Liveson JA. Thoracic radiculopathy related to collapsed thoracic vertebral bodies. J Neurol Neurosurg Psychiatry 1984; 47: 404-406.

25. Marinacci AA, Courville CB. Radicular syndromes simulating intra-abdominal surgi cal conditions. Am Surg 1962; 28:59-63.

26. Kim BJ, Park MH, Koh SB et al. Polyradiculomyelitis associated with clinically diagnosed tuberculous meningitis. Eur Neurol 2001; 46:156-157.

27. Levin KH. Neurologic manifestations of compressive radiculopathy of the first thoracic root. Neurology 1999; 53:1149-1151.

28. Morgan H, Abood C. Disc herniation at T1 2. Report of four cases and literature review. J Neurosurg 1998; 88:148-150.

29. Manifold SG, McCann PD. Cervical radic ulitis and shoulder disorders. Clin Orthop 1999; 368:105-113.

30. Hunt WE, Miller CA. Management of cervical radiculopathy. Clin Neurosurg 1986; 33:485-502.

31. Levin $\mathrm{KH}$. Electrodiagnostic approach to the patient with suspected radiculopathy. Neurol Clin 2002; 20:397-421.

32. Wilbourn AJ, Aminoff MJ. AAEE minimonograph \#32: The electrophysiologic examination in patients with radiculopathies. Muscle Nerve 1988; 11:1099-1114.

33. Aminoff MJ. Electrophysiological evaluation of root and spinal cord disease. Semin Neurol 2002; 22:197-204.

34. Gough JG, Koepke GH. Electromyographic determination of motor root levels in erec tor spinae muscles. Arch Phys Med Rehabil 1966; 47:9-11.

35. Dillingham TR, Lauder TD, Andary $M$ et al. Identification of cervical radiculopathies: optimizing the electromyographic screen. Am J Phys Med Rehabil 2001; 80:84-91.

36. Johnson ER, Powell J, Caldwell J et al. Intercostal nerve conduction and posterior rhizotomy in the diagnosis and treatment of thoracic radiculopathy. I Neurol Neurosurg Psychiatry 1974; 37:330-332.

37. Franson RC, Saal JS, Saal JA. Human disc phospholipase A2 is inflammatory. Spine 1992; 17:S129-S132.

38. Kantrowitz F, Robinson DR, McGuire MB et al. Corticosteroids inhibit prostaglandin production by rheumatoid synovia. Nature 1975; 258:737-739.

39. Claman HN. Corticosteroids and lymphoid cells. N Engl J Med 1972; 287:388-397.

40. Rinehart JJ, Balcerzak SP, Sagone AL et al. Effects of corticosteroids on human monocyte function. J Clin Invest 1974; 54:13371343.

41. Johansson A, Hao J, Sjolund B. Local corticosteroid application blocks transmission in normal nociceptive C-fibres. Acta Anaesthesiol Scand 1990; 34:335-338.

42. Byrod G, Otani K, Brisby $\mathrm{H}$ et al. Methylprednisolone reduces the early vascular permeability increase in spinal nerve roots induced by epidural nucleus pulposus application. J Orthop Res 2000; 18:983-987.

43. Woodard J, Herring S, Windsor R et al. Epidural procedures in spine pain and management. In Physiatric Procedures in Clinical Practice. Philadelphia, Hanly and Belfus, 1995.

44. Rowlingson JC, Kirschenbaum LP. Epidural analgesic techniques in the management of cervical pain. Anesth Analg 1986; 65: 938-942.

45. Shulman M. Treatment of neck pain with cervical epidural steroid injection. Reg Anesth 1986; 11:92.

46. Ferrante FM, Wilson SP, lacobo $\mathrm{C}$ et al. Clinical classification as a predictor of therapeutic outcome after cervical epidural steroid injection. Spine 1993; 18:730736.

47. Bush K, Hillier S. Outcome of cervical radiculopathy treated with periradicular/ epidural corticosteroid injections: A prospective study with independent clinical review. Eur Spine J 1996; 5:319-325.

48. Stenseth R, Berg EM, Bjella L et al. The influence of thoracic epidural analgesia alone and in combination with general anesthesia on cardiovascular function and myocardial metabolism in patients receiving beta-adrenergic blockers. Anesth Analg 1993; 77:463-468.

49. Guinard JP, Mavrocordatos P, Chiolero R et al. A randomized comparison of intravenous versus lumbar and thoracic epidural fentanyl for analgesia after thoracotomy. Anesthesiology 1992; 77:1108-1115.

50. Redekop GJ, Del Maestro RF. Diagnosis and management of spinal epidural abscess. Can J Neurol Sci 1992; 19:180-187.

51. Forrest JB. Management of chronic dorsal root pain with epidural steroid. Can $\mathrm{An}$ aesth Soc J 1978; 25:218-225.

52. Forrest JB. The response to epidural steroid injections in chronic dorsal root pain. Can Anaesth Soc J 1980; 27:40-46.

53. Mayer HM. Spine update. Percutaneous lumbar disc surgery. Spine 1994; 19:27192723.

54. Maroon JC. Current concepts in minimally invasive discectomy. Neurosurgery 2002; 51:S137-S145.

55. Quigley MR, Maroon JC. Laser discectomy: A review. Spine 1994; 19:53-56.

56. Brown MD. Update on chemonucleolysis. Spine 1996; 21:S62-S68.

57. Hoogland T, Scheckenbach C. Low-dose chemonucleolysis combined with percutaneous nucleotomy in herniated cervical disks. J Spinal Disord 1995; 8:228-232.

58. Nordby EJ, Fraser RD, Javid MJ. Chemonucleolysis. Spine 1996; 21:1102-1105.

59. Postacchini F. Management of herniation of the lumbar disc. J Bone Joint Surg Br 
$1999 ; 81: 567-576$

6o. Agre K, Wilson RR, Brim M et al. Chymodiactin postmarketing surveillance. Demographic and adverse experience data in 29,075 patients. Spine 1984; 9:479-485.

61. Young A, Getty J, Jackson A et al. Variations in the pattern of muscle innervation by the L5 and S1 nerve roots. Spine 1983; 8:616624.

62. Sasaki M, Takahashi T, Miyahara K et al. Effects of chondroitinase $A B C$ on intradiscal pressure in sheep: An in vivo study. Spine 2001; 26:463-468.

63. Takahashi T, Nakayama M, Chimura S et al. Treatment of canine intervertebral disc displacement with chondroitinase ABC. Spine 1997; 22:1435-1439.

64. Wittenberg RH, Oppel S, Rubenthaler FA et al. Five-year results from chemonucleolysis with chymopapain or collagenase: A prospective randomized study. Spine 2001; 26:1835-1841.

65. Hijikata S, Yamgishi M, Makayama T et al. Percutaneous discectomy. A new treatment method for lumbar disc herniation. J Toden Hosp 1975; 5:5-13.

66. Hijikata S. Percutaneous nucleotomy. A new concept technique and 12 years' experience. Clin Orthop 1989; 238:9-23.

67. Bonaldi G, Minonzio G, Belloni G et al. Percutaneous cervical diskectomy: Preliminary experience. Neuroradiology 1994; 36:483-486.

68. Kotilainen E. Percutaneous nucleotomy in the treatment of cervical disc herniation: Report of three cases and review. Minim Invasive Neurosurg 1999; 42:152-155.

69. Choy DS, Case RB, Fielding W et al. Percutaneous laser nucleolysis of lumbar disks. N Engl J Med 1987; 317:771-772.
70. Yeung A. Considerations for the use of the KTP laser for disc decompression and ablation. Spine: State of the Art Reviews 1993; 7:67-93.

71. Ohnmeiss DD, Guyer RD, Hochschuler SH. Laser disc decompression. The importance of proper patient selection. Spine 1994; 19:2054-2058.

72. Choy DS, Ascher PW, Ranu HS et al. Percutaneous laser disc decompression. A new therapeutic modality. Spine 1992; 17:949956.

73. Choy DS. Percutaneous laser disc decompression (PLDD): Twelve years' experience with 752 procedures in 518 patients. J Clin Laser Med Surg 1998; 16:325-331.

74. Siebert W. Percutaneous laser discectomy of cervical discs: Preliminary clinical results. J Clin Laser Med Surg 1995; 13:205207.

75. Chiu JC, Clifford TJ, Greenspan M et al. Percutaneous microdecompressive endoscopic cervical discectomy with laser thermodiskoplasty. Mt Sinai J Med 2000; 67: 278-282.

76. Nerubay J, Caspi I, Levinkopf $M$ et al. Percutaneous laser nucleolysis of the intervertebral lumbar disc. An experimental study. Clin Orthop 1997; 337:42-44.

77. Cvitanic OA, Schimandle J, Casper GD et al. Subchondral marrow changes after laser diskectomy in the lumbar spine: MR imaging findings and clinical correlation. $A J R$ Am J Roentgenol 2000; 174:1363-1369.

78. Hayashi K, Thabit G 3rd, Bogdanske JJ et al. The effect of nonablative laser energy on the ultrastructure of joint capsular collagen. Arthroscopy 1996; 12:474-481.

79. Chen YC, Lee SH, Saenz Y et al. Histologic findings of disc, end plate and neural el- ements after coblation of nucleus pulposus: An experimental nucleoplasty study. Spine J 2003; 3:466-470.

80. Chen Y, Lee SH, Chen DD. Intradiscal pressure study of percutaneous disc decompression with Nucleoplasty in human cadavers. Spine 2003; 28: in press.

81. Singh V. Percutaneous disc decompression for the treatment of chronic atypical cervical discogenic pain. Pain Physician 2004; 7:115-118.

82. Slipman CW, Bhagia SM, Frey ME et al. Nucleoplasty procedure for cervical radicular pain-initial case series. In Proceedings of Interventional Spinal Injection Society, August 8-10, 2003, Orlando, Florida, 104 105.

83. Sharps LS, Issac Z. Percutaneous disc decompression using Nucleoplasty. Pain Physician 2002; 5:121-126.

84. Derby R. Outcome comparison between IDET, combined IDET Nucleoplasty and biochemical injection treatment. In Proceedings of International Spinal Injection Society, 10th Annual Scientific Meeting, Austin, TX, September 7, 2002, 70-71.

85. Mochida J, Toh E, Nomura T et al. The risks and benefits of percutaneous nucleotomy for lumbar disc herniation. A 10-year longitudinal study. J Bone Joint Surg Br 2001; 83:501-505.

86. Saal JA, Saal JS. Intradiscal electrothermal treatment for chronic discogenic low back pain: A prospective outcome study with minimum 1-year follow-up. Spine 2000; 25:2622-2627.

87. Troussier B, Lebas JF, Chirossel JP et al. Percutaneous intradiscal radio-frequency thermocoagulation. A cadaveric study. Spine 1995; 20:1713-1718. 